\title{
High interleukin-10 production is associated with low antibody response to influenza vaccination in the elderly
}

\author{
Emanuela Corsini, ${ }^{*, 1}$ Luigi Vismara, ${ }^{\dagger}$ Laura Lucchi, ${ }^{*}$ Barbara Viviani, ${ }^{*}$ Stefano Govoni, ${ }^{\dagger}$ \\ Corrado L. Galli, ${ }^{*}$ Marina Marinovich, ${ }^{*}$ and Marco Racchi ${ }^{\dagger}$ \\ *Laboratory of Toxicology, Department of Pharmacological Sciences, University of Milan, Italy; and ${ }^{\dagger}$ Department of \\ Experimental and Applied Pharmacology, University of Pavia, Italy
}

\begin{abstract}
The present study was designed to determine the correlation among dehydroepiandrosterone (DHEA), cortisol plasma levels, and immune functionality at the time of vaccination with antibody response to influenza vaccination in young and old, healthy volunteers. Fifty-two elderly subjects, ages 63-85 years, and 14 young subjects, ages 26-41 years, entered the study. Plasma levels of DHEA and cortisol and in vitro cytokine production in response to lipopolysaccharide (LPS) and phytohaemagglutinin (PHA) by peripheral blood leukocytes were assessed at the time of vaccination, and antibody titer was measured before and 18 days after influenza virus vaccination. Elderly subjects were characterized by an increase in the cortisol:DHEA ratio, mainly as a result of a decrease in DHEA. A decrease in LPS-induced tumor necrosis factor $\alpha$ (TNF- $\alpha$ ), increased PHA-induced interleukin-10 (IL10) release, and similar PHA-induced interferon- $\gamma$ production were observed in elderly subjects compared with young volunteers. Lower antibody titer to influenza A virus was observed in elderly individuals, and the seroconversion factor was found to be correlated inversely with IL-10 production and correlated directly with TNF- $\alpha$ production and to a lesser extent, with the plasma level of DHEA. These results suggest that altered cytokine production in elderly subjects at the moment of vaccination can be predictive of a low response to influenza vaccination and warrant the study of strategies to improve protection afforded by the use of vaccines. J. Leukoc. Biol. 80: 376-382; 2006.
\end{abstract}

Key Words: immunosenescence $\cdot$ cytokines $\cdot$ dehydroepiandrosterone $\cdot$ aging

\section{INTRODUCTION}

Influenza is an acute respiratory illness of global importance, which causes considerable morbidity and mortality every year. Influenza virus can cause substantial morbidity across the age spectrum. The elderly are, however, especially vulnerable to the serious complications of influenza, and high rates of influenza-associated excess hospitalization or death, which exceed by several-fold the rates seen among most other age groups, have consistently been observed in many countries and across many seasons [1-3].

Given the increasing proportion of elderly people worldwide, a better understanding of the causes and mechanisms of immunosenescence is crucial to identify whether prevention might be beneficial to enhance quality of life and to reduce the cost of medical care in old age. Normal aging is indeed associated with a number of impaired immune responsiveness, such as reduction in response to recall antigen, alterations in $\mathrm{T}$ cell functions, which contribute to increased vulnerability to infectious disease and malignancy, and reduced responses to preventive vaccination in the elderly [4].

Today, in developed countries, influenza prophylaxis depends on the annual administration of a killed, trivalent influenza vaccine tailored each year to specific strains of the influenza virus. Vaccine is recommended for all individuals with chronic, underlying diseases and for those aged 65 years or older. Unfortunately, the present available influenza virus vaccine fails to generate protective immunity in $\sim 50 \%$ of old individuals [5]. In particular, the seroconversion, after vaccine, is $50 \%$ from 60 to 70 years old, $31 \%$ from 70 to 80 years old, and only $11 \%$ after the age of 80 . Yet, as far as public health is concerned, the vaccination reduces the morbidity by $25 \%$, admission to hospital by $20 \%$, pneumonia by $50 \%$, and mortality by $70 \%[6]$.

Improved vaccines or pharmacological intervention, which can overcome the decline in immune function with aging and/or induce broader immunity to novel pandemic strains, are considered a high priority $[7,8]$.

Many factors contribute to immunosenescence, including stem-cell defects, thymus involution, aging of resting immune cells, replicative senescence of clonally expanding cell, defects in antigen-presenting cells (APC), dysfunction in several signal transduction pathways, and dysregulation of the cytokine network [9-11]. We have recently shown in rodents and humans that a decreased expression in receptor for activated $\mathrm{C}$ kinase 1 (RACK-1), in the absence of differences in the expression of total protein kinase $\mathrm{C}$ (PKC) isoforms, underlies defective PKC activation and functional immune impairment with aging, such

\footnotetext{
${ }^{1}$ Correspondence: Laboratory of Toxicology, Department of Pharmacological Sciences, Faculty of Pharmacy, Via Balzaretti 9, 20133 Milan, Italy. E-mail: emanuela.corsini@unimi.it

Received March 13, 2006; revised April 9, 2006; accepted April 10, 2006; doi: 10.1189/jlb.0306190.
} 
as cytokine production and proliferation $[12,13]$. Furthermore, we found a positive correlation between plasma level of dehydroepindrosterone (DHEA), whose levels decrease with aging [14], and RACK-1 immunoreactivity, suggesting an important role of this hormone in maintaining RACK-1 expression and PKC $\beta$-mediated immune activation in leukocytes [12, 13].

Our understanding of the molecular mechanism of the immune response to influenza virus is still incomplete. During infection, the influenza virus interacts with airway cells, inducing the release of immunoreactive mediators, which attract inflammatory cells to the sites of infection and exert antiviral activities, providing an early defense against viral infection. Many cytokines are produced, involved in the initiation of the inflammatory response in addition to the recruitment and activation of specific lymphocytes (reviewed in refs. [15, 16]). The interplay with interleukin (IL)-1 $\beta$, tumor necrosis factor $\alpha$ $(\mathrm{TNF}-\alpha)$, interferon (IFN)- $\alpha / \beta$, IL-18, IFN- $\gamma$, and chemokines forms a complex, positive feed-back network leading to inflammatory response and the development of influenza-specific, cell-mediated immunity. Cytokine gene expression is associated with the activation of several signal transduction molecules, i.e., nuclear factor- $\mathrm{\kappa B}$, activated protein- 1 , signal transducer and activator of transcription, and IFN-regulatory factor, many of which are dependent on PKC activation [17-19].

The purpose of the present study was to investigate if the age-related impairment of the translocation of PKC, which underlies downstream defects in the in vitro activation of immune responses, was also relevant for the in vivo immune responsiveness, as assessed by response to influenza vaccination. We tested the hypothesis that an altered function of immune cells at the moment of vaccination may be in part responsible for a defective response to the vaccine in the elderly. We therefore investigated the correlation between DHEA, cortisol plasma levels, and in vitro cytokine production at the moment of vaccination with antibody response to influenza vaccination in young and old, healthy volunteers. As a result of their central role in regulating the immune response, including viral infection, we investigated the production of TNF- $\alpha$, IL-10, and IFN- $\gamma$ in response to nonantigen-specific stimuli, such as lipopolysaccharide (LPS) and phytohemagglutinin (PHA), using the whole blood assay, which is a simple method that reproduces the natural environment (autologous serum). It was used, as it requires less blood, and the risk of loss of minor lymphocyte subsets through density gradient is eliminated [20].

Overall, our study indicates that low plasma level of DHEA, decreased TNF- $\alpha$, and increased IL-10 production at the moment of vaccination are associated with lower antibody response to influenza vaccination and suggest possible means of pharmacological modulation of immune functions in the elderly.

\section{MATERIALS AND METHODS}

\section{Chemicals}

LPS from Escherichia coli serotype 0127:B8 and human $\beta$-actin antibody were obtained from Sigma Chemical Co. (St. Louis, MO), PHA was from Invitrogen (Paisley, UK), antibodies against RACK-1 were from Transduction Laborato- ries (Affinity, Nottingham, UK), and electrophoresis reagents were from BioRad (Richmond, CA). All reagents were purchased at the highest purity available.

\section{Study protocol}

In this study, a total of 66 healthy subjects living in the same geographical area of Northern Italy were recruited. These subjects included 52 elderly subjects (age 73.2 \pm 6.9 years, range 63-85; 37 females and 15 males) and 14 young subjects (age $30.4 \pm 4.8$ years, range $26-41$, nine females and five males). All elderly subjects were functionally independent. The ethical committee of the local Health Authorities approved the study, and all subjects signed an informed consent. All the clinical procedures and enrollment of the subjects were performed according to the guidelines of the Italian Health Authorities and the Declaration of Helsinki principles. Criteria for exclusion were abnormal laboratory values, medication known to affect the immune system (i.e., steroids), or patients suffering from malignancies, inflammations, and infections.

Prevaccination blood samples were collected just prior to vaccination in the early morning. Subjects were vaccinated in November 2004 by intramuscular injection with a commercially available, trivalent 2004/2005 influenza vaccine containing $15 \mu \mathrm{g}$ haemagglutinin of each of the following strains: A/New Caledonian/20/99 (H1N1), A/Fujian/411/2002 (H3N2), and B/Shangai/361/ 2002. Postvaccination sera were collected 18 days after vaccination at the same hour. Serum samples were separated into aliquots and stored at $-20^{\circ} \mathrm{C}$ until assayed. Over 95\% of the subject population had received yearly influenza immunization for the past 3 years as part of their routine clinical preventive care.

\section{Preparation of whole blood cells and cytokine production}

Blood samples were taken by venous puncture with sodium citrate $0.5 \mathrm{M}$ as anticoagulant. Sodium citrate was chosen instead of heparin or EDTA as anticoagulant, as functional assays were performed using the whole blood assay, and heparin may be contaminated with endotoxin; EDTA interferes with cell activation. Blood samples were diluted 1:10 in cell culture medium RPMI 1640 (Sigma Chemical Co.) containing $2 \mathrm{mM}$ L-glutamine, $0.1 \mathrm{mg} / \mathrm{ml}$ streptomycin, $100 \mathrm{IU} / \mathrm{ml}$ penicillin. Diluted blood samples were treated in the presence or absence of LPS at a final concentration of $1 \mu \mathrm{g} / \mathrm{ml}$ or PHA, 1.2 $\mu \mathrm{g} / \mathrm{ml}$, and incubated for $24 \mathrm{~h}$ or $96 \mathrm{~h}$ at $37^{\circ} \mathrm{C}$ in a humidified $5 \% \mathrm{CO}_{2}$ incubator for TNF- $\alpha$ and IL-10, IFN- $\gamma$ release, respectively. As a result of the variability in stimulation assays, the same lot of each reagent was used in all experiments. Cell-free supernatants obtained by centrifugation at 1200 revolutions per minute for $5 \mathrm{~min}$ were stored at $-20^{\circ} \mathrm{C}$ until measurement. Cytokine production was assessed by enzyme-linked immunosorbent assay (ELISA) using commercially available kits (Immunotools, Friesoythe, Germany). Results are expressed in $\mathrm{pg} / \mathrm{ml}$.

\section{Assay for DHEA and cortisol}

The levels of DHEA and cortisol in human plasma were determined by a commercially available enzyme immunoassay (Assay Design, Inc., Ann Arbor, MI) following the supplier's instructions. Results are expressed as ng/ml.

\section{Anti-influenza antibody assay}

Pre- and postvaccination immunoglobulin $\mathrm{G}$ antibody levels to Influenza A virus (H3N2) were assessed using a commercially available ELISA kit (Adaltis Italia, Casalecchio di Reno, Italy). Paired pre- and postvaccination sera samples from the same individual were tested simultaneously. Results are expressed as antibody titer, calculated using the semiquantitative plot enclosed in the kit and as the seroconversion factor, which was calculated as the ratio of the mean titer before vaccination:titer after vaccination.

\section{Western blot analysis}

For RACK-1 and $\beta$-actin expression in leukocytes, $1.0 \mathrm{ml}$ blood was treated with ammonium chloride to remove red cells, and then the remaining leukocytes were lysed in $100 \mu \mathrm{l}$ homogenization buffer $(50 \mathrm{mM}$ Tris, $150 \mathrm{mM} \mathrm{NaCl}$, $5 \mathrm{mM}$ EDTA, $\mathrm{pH}$ 7.5, 0.5\% Triton X-100, $50 \mu \mathrm{M}$ phenylmethylsulfonyl fluoride, $2 \mu \mathrm{g} / \mathrm{mL}$ aprotinin, $1 \mu \mathrm{g} / \mathrm{mL}$ pepstatin, and $1 \mu \mathrm{g} / \mathrm{mL}$ leupeptin) and 
denatured for $10 \mathrm{~min}$ at $100^{\circ} \mathrm{C}[21]$. The protein content of the cell lysate was measured using a commercial kit (Bio-Rad). The cell proteins $(30 \mu \mathrm{g})$ were electrophoresed into a $12 \%$ sodium dodecyl sulfate-polyacrylamide gel under reducing conditions. The proteins were then transferred to polyvinylidene difluoride membranes (Amersham, Little Chalfont, UK). The different proteins were visualized using RACK-1 (1:2500) and $\beta$-actin (1:5000) primary antibodies and developed using enhanced chemiluminescence (Amersham). The image of the immunoblotting was acquired with a Nikon charged-coupled device video camera module. The optical density of the bands was calculated and analyzed by means of the Image 1.47 program for digital image processing (Wayne Rasband, Research Service Branch, National Institute of Mental Health, National Institutes of Health, Bethesda, MD).

\section{Statistical analysis}

Data are expressed as mean \pm SEM. Statistical analysis was performed using GraphPad InStat Version 3.0a for Macintosh (GraphPad Software, San Diego, CA). Statistical differences were determined using the unpaired $t$-test or a multiple comparison test, as indicated in the legends. Spearman correlation was used to analyze the correlation among different parameters considered. Effects were designated significant if $P \leq 0.05$.

\section{RESULTS}

A total of 66 healthy subjects, 52 elderly (63-85 years old) and 14 young (26-41 years old), were enrolled and completed the study. The age and sex distributions of the subjects in the study are shown in Table 1. Blood samples were taken on the same day of vaccination, prior to injection, for hormone levels, functional analysis, and influenza A virus antibody titer, and 18 days after vaccination to determine the seroconversion factor.

\section{Hormone levels}

The age-related increase in the cortisol:DHEA ratio is considered to be the major determinant of immunological changes observed during aging. As shown in Figure 1, the elderly subjects enrolled into the study were characterized by a dramatic increase in the cortisol:DHEA ratio (calculated as mean of the individual cortisol:DHEA ratio of each subject): from $7.11 \pm 1.14$ in the young to $29.8 \pm 4.45$ in the elderly $(P<0.0001)$. This increase was mainly a result of a significant reduction in the levels of DHEA (from 27.44 \pm 1.70 to $12.28 \pm 1.10 \mathrm{ng} / \mathrm{ml}, P<0.0001)$ rather than cortisol, whose levels only increase slightly in the elderly (from 179.19 \pm 14.98 to $213.87 \pm 7.60 \mathrm{ng} / \mathrm{ml}, P=0.0398$ ).

\section{Cytokine production}

Confirming our previous results [13], peripheral blood leukocytes obtained from old donors were characterized by a statistically significant reduction in RACK-1 expression: $0.28 \pm$ 0.02 versus $0.48 \pm 0.04$ RACK-1: $\beta$-actin ratio in old versus young donors, respectively $(P<0.0001)$. Compromised signal

TABLE 1. Demographics of Study Participants

\begin{tabular}{lcrr}
\hline \hline & Total & \multicolumn{1}{c}{ Men } & \multicolumn{1}{c}{ Women } \\
\hline Young & $14(30.4 \pm 1.3)$ & $5(31.4 \pm 2.4)$ & $9(29.8 \pm 1.5)$ \\
Elderly & $52(73.2 \pm 1.0)$ & $15(73.1 \pm 2.2)$ & $37(73.2 \pm 1.0)$ \\
\hline
\end{tabular}

Mean of age in years \pm SE in parentheses. transduction machinery is likely to be associated with alteration in response to immune stimulation. Thus, to characterize the functionality of the immune system in young and elderly subjects, the production of TNF- $\alpha$, IL-10, and IFN- $\gamma$ was evaluated after in vitro stimulation of whole blood with LPS and PHA. The optimal time and stimuli concentrations were identified in preliminary experiments for each cytokine. For TNF- $\alpha$ production, cells were stimulated for $24 \mathrm{~h}$ with $1 \mu \mathrm{g} / \mathrm{ml}$ LPS, and for IL-10 and IFN- $\gamma$, cells were stimulated for $96 \mathrm{~h}$ with $1.2 \mu \mathrm{g} / \mathrm{ml}$ PHA. The spontaneous release of all cytokines investigated as well as their plasma levels were below the limit of detection before and after vaccination (data not shown). Figure 2 shows the production of TNF- $\alpha$, IL-10, and IFN- $\gamma$ by blood cells in young and elderly at the moment of influenza vaccination. The elderly subjects were indeed characterized by altered cytokine production. A statistically significant decrease in LPS-induced TNF- $\alpha$ release (from $1152 \pm 185$ in the young to $799 \pm 80 \mathrm{pg} / \mathrm{ml}$ in the elderly, $P=0.0495$ ), a statistically significant increase in PHA-induced IL-10 release (from $97 \pm 54.7$ to $458 \pm 34 \mathrm{pg} / \mathrm{ml}, P<0.0001$ ), and similar IFN- $\gamma$ release compared with young subjects $(4688 \pm 424$ and $4208 \pm 252 \mathrm{pg} / \mathrm{ml}$ in young and elderly, respectively) were observed. IL-10 and IFN- $\gamma$ production was also assessed following $96 \mathrm{~h}$ stimulation with LPS. As observed for stimulation with PHA, LPS-induced IL-10 production was increased in the elderly (from $12 \pm 4 \mathrm{pg} / \mathrm{ml}$ in the young to $51 \pm 20 \mathrm{pg} / \mathrm{ml}$ in the elderly, $P=0.0108)$. On the contrary, LPS-induced IFN- $\gamma$ production was reduced significantly in the elderly (from $421 \pm 29$ $\mathrm{pg} / \mathrm{ml}$ in the young to $120 \pm 7 \mathrm{pg} / \mathrm{ml}$ in the elderly, $P=0.0074)$.

\section{Antibody response to influenza vaccination and relationship with cytokine production}

To determine the response to influenza vaccination, the antibody titer to influenza $\mathrm{A}$ virus was assessed before and 18 days after vaccination. No local adverse effects to the influenza vaccine were reported in both groups. A lower antibody titer to influenza A virus following vaccination was observed in aged individuals (from $786 \pm 203$ in the young to $291 \pm 57$ in the elderly, $P=0.0016$ ). As shown in Figure 3A, the elderly had a significantly lower seroconversion factor than the young (from $2.25 \pm 0.35$ in the young to $1.08 \pm 0.10$ in the elderly, $P<0.0001$ ). The seroconversion factor (Fig. 3, B and C) was correlated directly with plasma level of DHEA (linear correlation $\mathrm{r}=0.363, P=0.0034)$ and inversely correlated with IL-10 production (linear correlation $\mathrm{r}=-0.484, P<0.0001$ ). Furthermore, a direct correlation with TNF production (linear correlation $\mathrm{r}=0.3997, P=0.0012$ ) was observed, and no correlation was found with IFN- $\gamma$ production or with cortisol level (not shown). Finally, the decreased TNF production was correlated to plasma levels of DHEA (linear correlation $r=0.326$, $P=0.0076$; not shown), and IL-10 release was strongly correlated (inverse correlation $r=-0.490, P<0.0001$ ) with the plasma levels of DHEA (Fig. 4).

\section{DISCUSSION}

A predictable influenza pandemic threat has highlighted the need for more effective influenza vaccines, antiviral drugs, as 


\section{A}
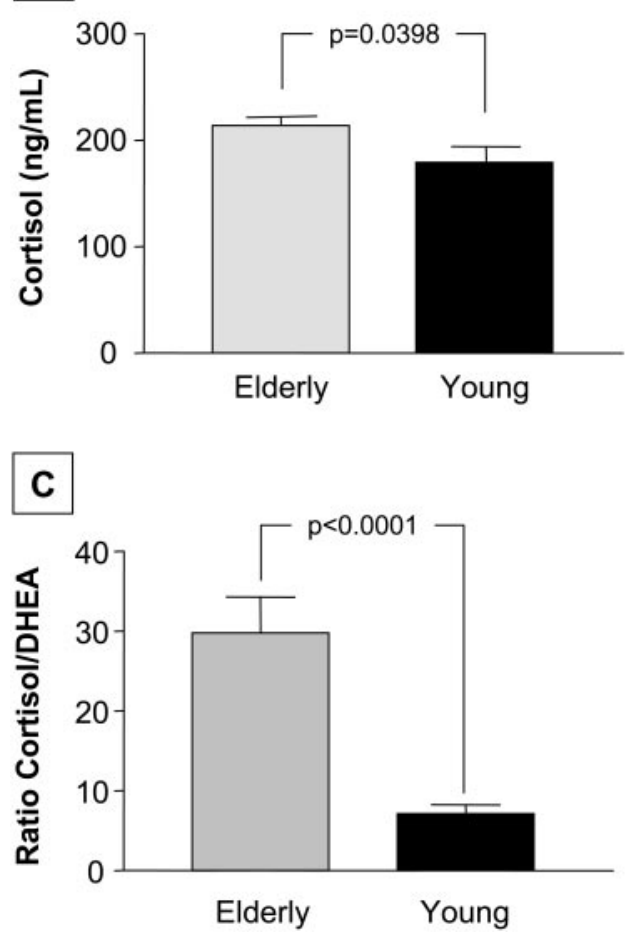

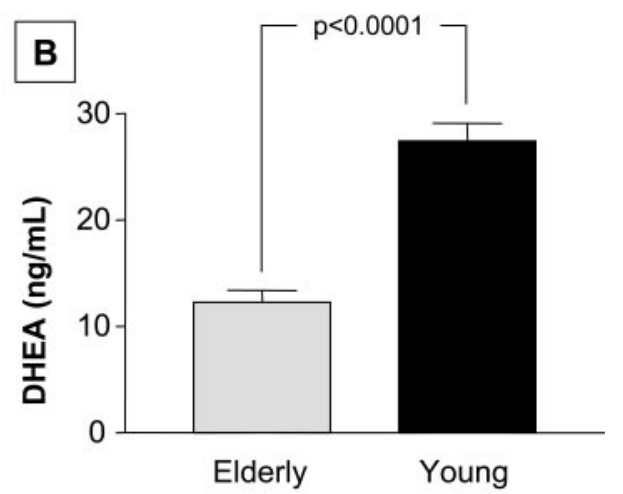

Fig. 1. Hormone profile of young and elderly subjects at the moment of influenza vaccination. (A) Plasma level of cortisol. (B) Plasma levels of DHEA. (C) Ratio cortisol:DHEA. Each value represents the mean \pm SEM. Statistical analysis has been performed by unpaired $t$-test. The $P$ value is reported in the figure. well as development of strategies to improve the response in at-risk populations, such as the elderly [22]. This is particularly stressed by the recent outbreak of avian viruses and the possibility that these will transfer to humans. Accordingly, the purpose of the present investigation was to correlate antibody response to influenza vaccination in young and old, healthy subjects with hormonal levels and immune functionality, as assessed by cytokine production, at the moment of vaccination. In this study, we found that low plasma level of DHEA, decreased TNF- $\alpha$, and increased IL-10 production at the moment of vaccination are associated with lower antibody response to influenza vaccination.
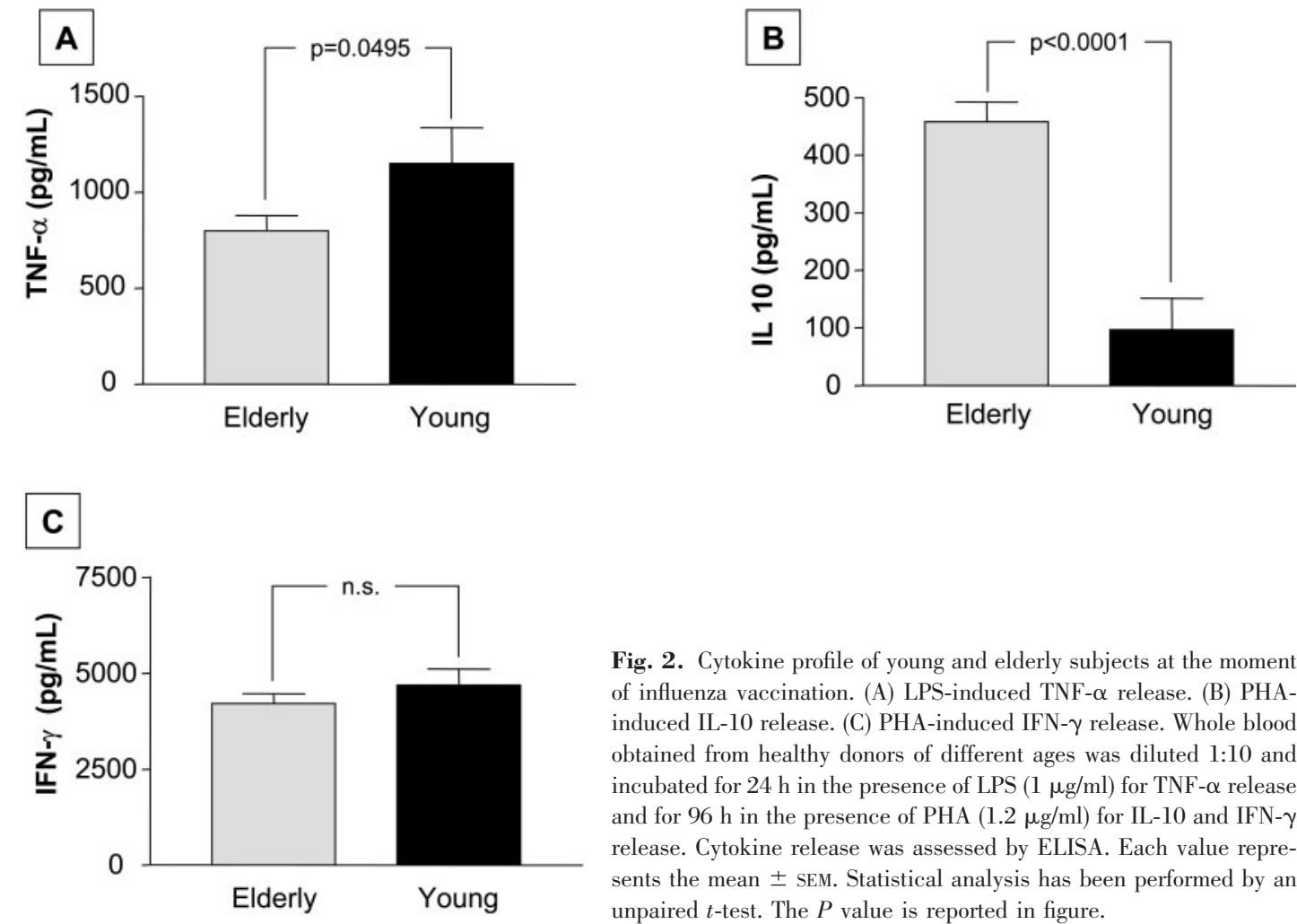

Fig. 2. Cytokine profile of young and elderly subjects at the moment of influenza vaccination. (A) LPS-induced TNF- $\alpha$ release. (B) PHAinduced IL-10 release. (C) PHA-induced IFN- $\gamma$ release. Whole blood obtained from healthy donors of different ages was diluted 1:10 and incubated for $24 \mathrm{~h}$ in the presence of LPS $(1 \mu \mathrm{g} / \mathrm{ml})$ for TNF- $\alpha$ release and for $96 \mathrm{~h}$ in the presence of PHA $(1.2 \mu \mathrm{g} / \mathrm{ml})$ for IL-10 and IFN- $\gamma$ release. Cytokine release was assessed by ELISA. Each value represents the mean \pm SEM. Statistical analysis has been performed by an unpaired $t$-test. The $P$ value is reported in figure. 

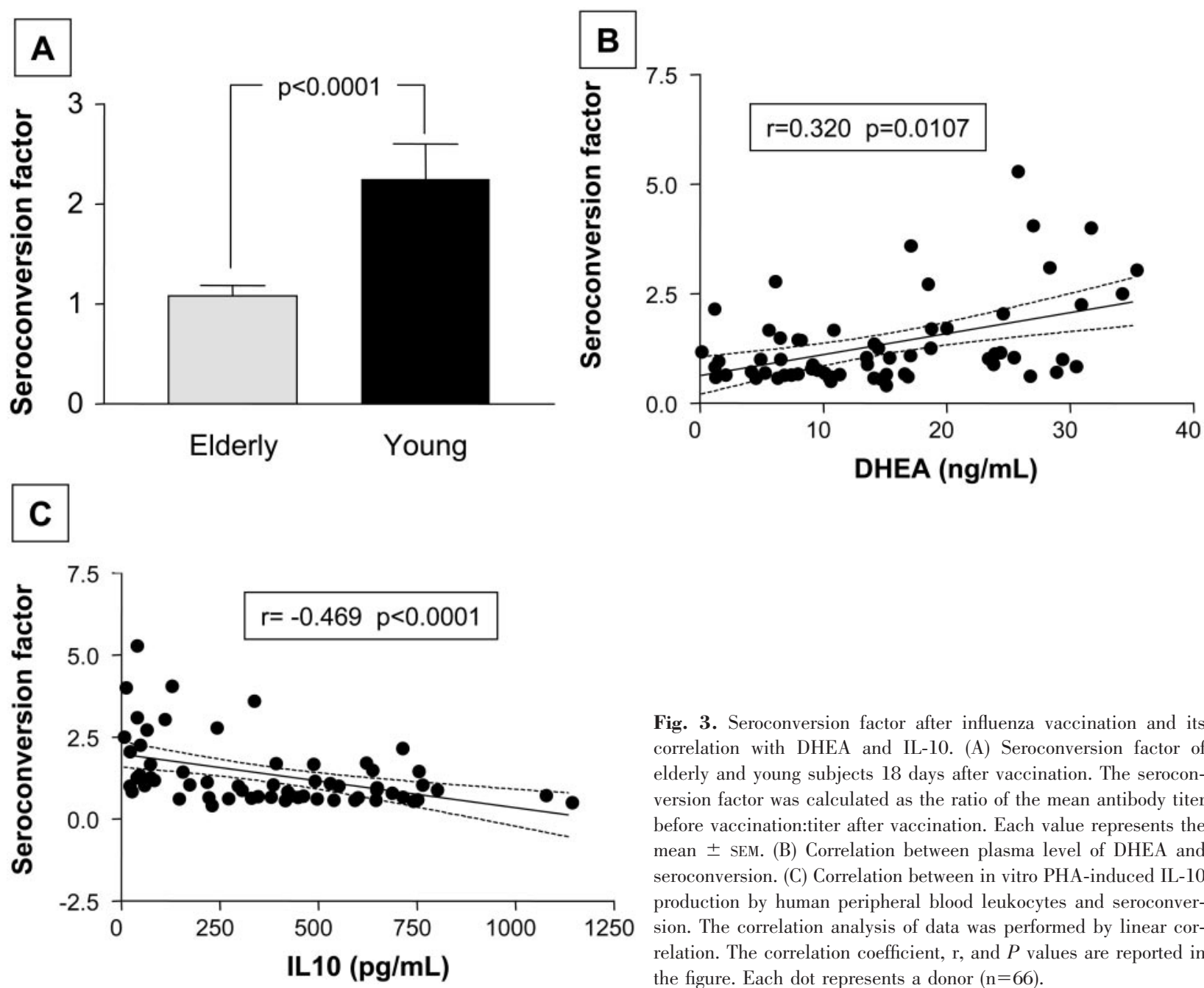

Fig. 3. Seroconversion factor after influenza vaccination and its correlation with DHEA and IL-10. (A) Seroconversion factor of elderly and young subjects 18 days after vaccination. The seroconversion factor was calculated as the ratio of the mean antibody titer before vaccination:titer after vaccination. Each value represents the mean \pm SEM. (B) Correlation between plasma level of DHEA and seroconversion. (C) Correlation between in vitro PHA-induced IL-10 production by human peripheral blood leukocytes and seroconversion. The correlation analysis of data was performed by linear correlation. The correlation coefficient, $\mathrm{r}$, and $P$ values are reported in the figure. Each dot represents a donor $(n=66)$.

The senescent immune system displays reduced responsiveness, and this has to be overcome if therapeutic vaccination is to be of benefit for the patient. Although the defects are quite well-characterized, the molecular mechanisms, inducing and sustaining immunosenescence and ways to overcome them, are

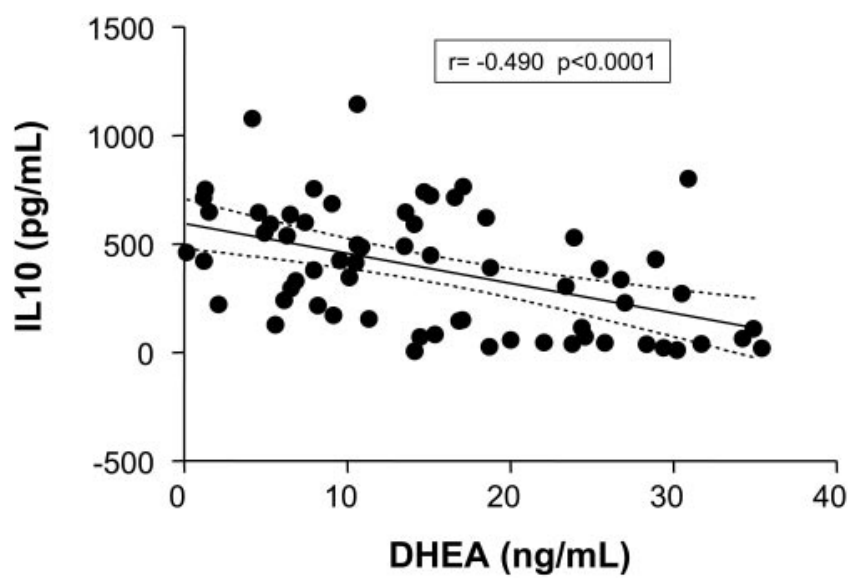

Fig. 4. Correlation between plasma level of DHEA and in vitro PHA-induced IL-10 production by human peripheral blood leukocytes. Correlation analysis of data was performed by linear correlation. The correlation coefficient, $r$, and $P$ values are reported in the figure. Each dot represents a donor $(n=66)$. still to be explored in more detail. Substantial data from animal studies have demonstrated a stimulatory effect of DHEA on immune function. We previously demonstrated in vitro and in vivo that DHEA can restore the age-related, defective TNF- $\alpha$ production in macrophages and mitogen-induced splenocyte proliferation [12]. May et al. [23] demonstrated that DHEA administration reversed corticosteroid and stress-induced inhibition of immune function, Loria et al. [24] showed that DHEA administration has a protective effect against systemic Coxsackie virus and Herpes simplex type 2 encephalitis, and Daynes et al. [25] found that it can enhance IL-2 production by activated murine T cells. In a limited clinical trial, it has been demonstrated that orally administered DHEA (50 mg/daily) to elderly men with low-serum DHEA safely activated several immune functions within 2-20 weeks of treatment, including B and $\mathrm{T}$ cell mitogenic response and PHA-induced IL-2 production, suggesting potential therapeutic benefits of DHEA supplementation in immunodeficient states [26]. On the contrary, although highly effective in sustaining the response to vaccination in aged rodents, a short course of DHEA treatment, 2 days prior and 2 days after vaccination, failed to improve the age-related, declined response to influenza vaccination in elderly human subjects [27]. Overall, too little is known about the effects of DHEA supplementation on the human immune system, and it is still premature to relate these findings to 
routine clinical applications. Nevertheless, in our investigation, higher baseline DHEA levels were predictive of better immunization against influenza and may suggest that DHEA supplementation may be beneficial. Other methods of increasing immune response in the elderly to influenza vaccine may include the addition of IL-2 to vaccine protocol, the use of liposome carriers or diphtheria toxoid adjuvants, or using alternative routes of immunization [28-31].

Concerning the immune system functionality, age-related changes in cytokine production by immune cells are likely to contribute to the decreased antibody production seen after influenza vaccination in the elderly. Numerous studies have investigated the age-related change in cytokine production after specific and nonspecific stimulation, and contradictory results have been reported [32-34]. This may be a result of sample sizes, varying states of health and lifestyle, different stimuli, and culture conditions. Results from our investigation show decreased TNF- $\alpha$ production, unchanged PHA-induced IFN- $\gamma$ production, and decreased LPS-induced IFN- $\gamma$ production in the elderly, together with increased mitogen-induced IL-10 production. IL-10 and TNF- $\alpha$ are cytokines, which have complex and predominantly opposing roles in the activation of the immune response $[35,36]$. The increased production of IL-10 in the elderly, observed in response to LPS and PHA, is likely to inhibit the maturation of APC, hampering, together with decreased TNF- $\alpha$ production, their migration to draining lymph nodes, compromising the subsequent induction of the specific immune response. Furthermore, IL-10 can induce long-term, antigen-specific anergy in $\mathrm{CD} 4^{+} \mathrm{T}$ cells. Thus, it is intriguing that the possession of an anti-inflammatory genotype (high IL-10 and low TNF- $\alpha$ production) is increased significantly in male centenarians [37]. High TNF- $\alpha$ production may be an important and necessary part of the normal host response to pathogens, but its overproduction may cause immune-inflammatory diseases and eventually death. An anti-inflammatory phenotype (high IL-10 production) may be highly advantageous in the last decades of life, owing to the chronic proinflammatory status, which develops in the subjects with age [37, 38]. Thus, it is tempting to speculate that the presence of "high IL-10/low TNF- $\alpha$ " could be favorable in protecting against age-related diseases, particularly, neurodegenerative diseases $[39,40]$, but conversely, it could hamper the immune response to infections and vaccine.

Overall, our study contributes to the understanding of the effects of age on innate and adaptive immunity, which accompany the response to influenza vaccine. It represents an important bridge between basic immune function and clinical immunology in the hope of generating an effective reconstitution to improve immune response in the elderly. The results obtained may contribute to define better strategies to improve the response to vaccination in the elderly and underlie the necessity to overcome immunosenescence at the moment of vaccination to obtain a better response.

\section{ACKNOWLEDGMENTS}

This work was supported partially by FIRST funds from the University of Milan to C. L. G., by the Center for Toxicological
Risk Assessment of the University of Milan, and by the Fondo Ateneo Ricerca of the University of Pavia to M. R. We are also grateful to the officials of the A.S.L 1-Milano for approving and supporting our research and to the mayor, Mr. Cattoni, and all the city council of the town of Rosate (MI, Italy) for logistic support and help with recruitment. Finally, we express our gratitude to the population of Rosate for their enthusiastic participation in this project.

\section{REFERENCES}

1. Kohn, R. R. (1982) Cause of death in very old people. JAMA 247, 2793-2797.

2. Fleming, D. M., Elliot, A. J. (2005) The impact of influenza on the health and health care utilization of elderly people. Vaccine 23, S1-S9.

3. Nichol, K. L. (2005) Influenza vaccination in the elderly: impact on hospitalization and mortality. Drugs Aging 22, 495-515.

4. Ershler, W. B. (1993) The influence of an aging immune system on cancer incidence and progression. J. Gerontol. 48, B3-B7.

5. Setia, U., Serventi, I., Lorenz, P. (1985) Factors affecting the use of influenza vaccine in institutionalized elderly. J. Am. Geriatr. Soc. 33, $856-858$.

6. Bouree, P. (2003) Immunity and immunization in elderly. Pathol. Biol. (Paris) 51, 581-585.

7. Katz, J. M., Plowden, J., Renshaw-Hoelscher, M., Lu, X., Tumpey, T. M., Sambhara, S. (2004) Immunity to influenza: the challenges of protecting an aging population. Immunol. Res. 29, 113-124.

8. McElhaney, J. E. (2005) The unmet need in the elderly: designing new influenza vaccines for older adults. Vaccine 23 (Suppl. 1), S10-S25.

9. Doria, G., Biozzi, G., Mouton, D., Covelli, V. (1997) Genetic control of immune responsiveness, ageing and tumor incidence. Mech. Ageing Dev. 96, $1-13$.

10. Hirokawa, K. (1999) Age-related changes of signal transduction in T cells. Exp. Gerontol. 34, 7-18.

11. Pawelec, G., Akbar, A., Caruso, C., Solana, R., Grubeck-Loebenstein, B. Wikby, A. (2005) Human immunosenescence: is it infectious? Immunol. Rev. 205, 257-268.

12. Corsini, E., Lucchi, L., Meroni, M., Racchi, M., Solerte, B., Fioravanti, M., Viviani, B., Marinovich, M., Govoni, S., Galli, C. L. (2002) In vivo dehydroepiandrosterone restores age-associated defects in protein kinase $\mathrm{C}$ signal transduction pathway and related functional responses. J. Immunol. 168, 1753-1758.

13. Corsini, E., Racchi, M., Sinforiani, E., Lucchi, L., Viviani, B., Rovati, G. E., Govoni, S., Galli, C. L., Marinovich, M. (2005) Age-related decline in RACK-1 expression in human leukocytes is correlated to plasma levels of dehydroepiandrosterone. J. Leukoc. Biol. 77, 247-256.

14. Vermeulen, A. (1995) Dehydroepiandrosterone sulfate and ageing. Ann. N. Y. Acad. Sci. 774, 121-127.

15. Julkunen, I., Sareneva, T., Pirhonen, J., Ronni, T., Melen, K., Matikainen, S. (2001) Molecular pathogenesis of influenza A virus infection and virus-induced regulation of cytokine gene expression. Cytokine Growth Factor Rev. 12, 171-180.

16. Van Reeth, K. (2000) Cytokines in the pathogenesis of influenza. Vet. Microbiol. 74, 109-116.

17. Saijo, K., Mecklenbrauker, I., Schmedt, C., Tarakhovsky, A. (2003) B cell immunity regulated by the protein kinase C family. Ann. N. Y. Acad. Sci. 987, 125-134.

18. Tan, S. L., Parker, P. J. (2003) Emerging and diverse roles of protein kinase $\mathrm{C}$ in immune cell signaling. Biochem. J. 376, 545-552.

19. Lucas, P. C., McAllister-Lucas, L. M., Nunez, G. (2004) NF-кB signaling in lymphocytes: a new cast of characters. J. Cell Sci. 117, 31-39.

20. De Groote, D., Zangerle, P. F., Gevaert, Y., Fassotte, M. F., Gegin, Y., Noizat-Pirenne, F., Pirenne, J., Gathy, R., Lopez, M., Dehart, I., et al. (1992). Direct stimulation of cytokines (IL-1 $\beta$, TNF- $\alpha$, IL-6, IFN- $\gamma$ and GM-CSF) in whole blood. I. Comparison with isolated PBMC stimulation. Cytokine 4, 239-248.

21. Laemmli, U. K. (1970) Cleavage of structural proteins during the assembly of the head of bacteriophage T4. Nature 227, 680-685.

22. Kandel, R., Hartshorn, K. L. (2005) Novel strategies for prevention and treatment of influenza. Expert Opin. Ther. Targets 9, 1-22.

23. May, M., Holmes, E., Rogers, W., Poth, M. (1990) Protection from glucorticoid-induced thymic involution by dehydroepiandrosterone. Life Sci. 46, 1627-1631. 
24. Loria, R. M., Inge, T. H., Cook, S. S., Szaki, A. K., Regelson, W. (1988) Protection against acute lethal viral infection with the naïve steroid dehydroepiandrosterone (DHEA). J. Med. Virol. 26, 301-314.

25. Daynes, R. A., Dudley, D. J., Araneo, B. A. (1990) Regulation of murine lymphokine production in vivo. II. Dehydropeiandrosterone is a natural enhancer of interleukin-2 synthesis by helper T cells. Eur. J. Immunol. 20, 793-802.

26. Khorram, O., Vu, L., Yen, S. C. (1997) Activation of immune function by dehydroepiandrosterone (DHEA) in age-advanced men. J. Gerontol. A Biol. Sci. Med. Sci. 52, M1-M7.

27. Danenberg, H. D., Ben-yehuda, A., Zakay-Rones, Z., Gross, D. J., Friedman, G. (1997) Dehydroepinadrosterone treatment is not beneficial to the immune response to influenza in the elderly subjects. J. Clin. Endocrinol. Metab. 82, 2911-2914.

28. Provinciali, M., Di Stefano, G., Colombo, M., Della Croce, F., Gandolfi, M. C., Daghetta, L., Anichini, M., Della Bitta, R., Fabris, N. (1994) Adjuvant effect of low-dose interleukin-2 on antibody response to influenza virus vaccination in healthy elderly subjects. Mech. Ageing Dev. 77, $75-82$.

29. Gluck, R., Mischler, R., Finkel, B., Que, J. U., Scarpa, B., Cryz, S. J. (1994) Immunogenicity of new virosome influenza vaccine in elderly people. Lancet 344, 160-163.

30. Gravenstein, S., Drinka, P., Duthie, E. H., Miller, B. A., Brown, C. S., Hensley, M., Circo, R., Langer, E., Ershler, W. B. (1994) Efficacy of an influenza hemagglutinin-diphtheria toxoid conjugate vaccine in elderly nursing home subjects during an influenza outbreak. J. Am. Geriatr. Soc. 42, 245-251.

31. Belshe, R. B., Newman, F. K., Cannon, J., Duane, C., Treanor, J., Van Hoecke, C., Howe, B. J., Dubin, G. (2004) Serum antibody responses after intradermal vaccination against influenza. N. Engl. J. Med. 351, 2286-2294.
32. Bernstein, E. D., Gardner, E. M., Abrutyn, E., Gross, P., Murasko, D. M. (1998) Cytokine production after influenza vaccination in a healthy elderly population. Vaccine 16, 1722-1731.

33. Caruso, C., Candore, G., Cigna, D., DiLorenzo, G., Sireci, G., Dieli, F., Salerno, A. (1996) Cytokine production pathway in the elderly. Immunol. Res. 15, 84-90.

34. Rink, L., Cakman, I., Kirchner, H. (1998) Altered cytokine production in the elderly. Mech. Ageing Dev. 102, 199-209.

35. Moore, K. W., de Waal Malafyt, R., Coffman, R. L., O’Garra, A. (2001) Interleukin-10 and the interleukin-10 receptor. Annu. Rev. Immunol. 19, $683-765$.

36. Makhatadze, N. J. (1998) Tumor necrosis factor locus: genetic organization and biological implications. Hum. Immunol. 59, 571-579.

37. Lio, D., Scola, L., Crivello, A., Colonna-Romano, G., Candore, G., Bonafe, M., Cavallone, L., Marchegiani, F., Olivieri, F., Franceschi, C., Caruso, C. (2003) Inflammation, genetics, and longevity: further studies on the protective effects in men of IL-10 -1082 promoter SNP and its interaction with TNF- $\alpha-308$ promoter SNP. J. Med. Genet. 40, 296-299.

38. Krabbe, K. S., Pedersen, M., Bruunsgaard, H. (2004) Inflammatory mediators in the elderly. Exp. Gerontol. 39, 687-699.

39. Franceschi, C., Valensin, S., Lascai, F., Olivieri, F., Licastro, F., Grimaldi, L. M., Monti, D., De Benetictis, G., Bonafe, M. (2001) Neuroinflammation and the genetics of Alzheimer's disease: the search for a pro-inflammatory phenotype. Aging 13, 163-170.

40. McCusker, S. M., Curran, M. D., Dynan, K. B., McCullagh, C. D., Urquhart, D. D., Middleton, D., Patterson, C. C., McIlroy, S. P., Passmore, A. P. (2001) Association between polymorphism in the regulatory region of gene encoding tumor necrosis factor $\alpha$ and risk of Alzheimer's disease and vascular dementia: a case control study. Lancet 357, 436-439. 